\title{
Analyzing development patterns in research networks and technology
}

\author{
Patrick Wolf $^{1}$ (D) Tobias Buchmann ${ }^{1}$
}

Received: 6 April 2020 / Accepted: 1 January 2021/ Published online: 14 April 2021

(C) The Author(s) 2021

\begin{abstract}
The present paper analyzes development patterns in research networks and technology as well as their co-evolution by the example of the currently highly transformative German automotive industry. We therefore introduce a consistent network-based approach for measuring change in research networks and the technological composition of patents. Our results show that the applied method is particularly useful for identifying structural similarities and main structural changes in research and patent networks. Further, the investigation of the co-evolutionary processes indicates that, regarding the German automotive industry, changes in technology lead to structural changes in the research network.
\end{abstract}

Keywords Technological change $\cdot$ Innovation networks $\cdot$ Network dynamics $\cdot$ Coevolution

JEL classification $\mathrm{O} 3 \cdot \mathrm{O} 30$

\section{Introduction}

Change and dynamics in both research networks and technology are highly relevant research fields in innovation economics. However, previous concepts and approaches for surveying and measuring such dynamics differ considerably. There is a large number of empirical studies on measuring technological change, using a broad spectrum of approaches ranging from patent counts (Archibugi and Planta 1996) over citations (Verspagen 2007) to the analysis of keywords in documents (Joung and

Patrick Wolf

patrick.wolf@zsw-bw.de

Tobias Buchmann

tobias.buchmann@zsw-bw.de

1 Center for Solar Energy and Hydrogen Research Baden-Württemberg (ZSW), Stuttgart, Germany 
Kim 2017). Conversely, studies in the field of network research have been based on a static point of view for a long time (Baum et al. 2003; Buchmann and Pyka 2015) leading to insufficient knowledge regarding the general "empirical understanding of innovation network evolution" (Buchmann and Pyka 2015, p.116). Furthermore, currently existing network indicators tend to only depict specific aspects of the network structure and barely the network as a whole, making it difficult to look at its general structural development. This also has consequences on a possible comparing view between technology development and network dynamics, as we need a deep insight into innovation system dynamics to understand technological change (Hekkert et al. 2007).

Previous literature already suggested an existing co-evolution between research networks and technology (Orsenigo et al. 2001; Murray 2002) and indicates interesting effects of mutual influence. On the one hand, changes in research networks can be seen as drivers of technological development (Deeds and Hill 1996) while on the other hand, technological development may also influence the composition and structure of innovation networks (Anderson and Tushman 1990). As co-evolution can be seen as an important aspect in economics as well as sociology of technological change (Rosenberg 1982), it is not surprising that co-evolutionary processes regarding technology and innovation networks have already aroused the interest of the research community (Orsenigo et al. 2001; Murray 2002; Gilsing 2005). However, regarding especially highly transformative technological areas, empirical evidence is still scarce. Further, there currently seems to be a lack of consistent measurement to facilitate the comparability between the two processes.

Based on these shortcomings, the aim of this paper is twofold: First, it aims at developing a new consistent method for analyzing change in research and technology networks. The second aim is to provide deeper insight into transformation processes within a currently highly transformative technological area: the automotive industry. We therefore adapt a methodology of a recent publication by Parraguez et al. (2020) and modify it for creating a network-based indicator for measuring both structural change in research networks and technological change. Afterward, we use this indicator to analyze transformation processes in the German automotive research network and the structure of automotive-related German patents as well as their co-evolution.

The paper is structured as follows. In the second part, we give a short theoretical review on both technological change and structural change in research networks as well as their respective measurement in the literature. This is followed by a short review of corresponding co-evolutionary research in literature and an excursus about the change in the German automotive innovation system. The third part gives insight into the applied method and used data, while the fourth part presents and discusses the results. In the end, the fifth part provides a short conclusion.

\section{Theoretical part}

\subsection{Technological change}

\subsubsection{Theoretical background}

Most literature agrees that technological change results from the recombination of existing and new technological capabilities, which in turn can be seen as the main 
source of technological novelty (Strumsky et al. 2012). As technological knowledge can be seen as cumulative, technological change often proceeds gradually, ordered, and over a longer period, leading to a stabilization of technological paradigms (Dosi et al. 1988). A technological paradigm entails "a 'pattern' of a solution of selected technoeconomic problems based on highly selected principles derived from the natural sciences, jointly with specific rules aimed to acquire new knowledge and safeguard it, whenever possible, against rapid diffusion to the competitors" (Dosi and Nelson 2010, p.14). Technological paradigms lead to technological trajectories since the community of engineers follows a similar search path. Technological trajectories are influenced by engineers, but also by other groups such as users, suppliers, scientists, and banks (Geels 2002). "The avenue of knowledge production can be directed by technological paradigms or by technological trajectories, which reduce the degrees of freedom" (Buchmann 2015, p.84 refering to Dosi and Nelson 2010) and tend to correspond to rather small steps in technological change. The persistence of such trajectories is supported by diverse technological as well as institutional barriers, which in most cases hinder more radical changes. It is for this reason that in the past literature on technological (regime) change has mainly focused on the "persistence of change along well-defined pathways" (Berkhout 2002, p.4).

However, despite the inter-locked and inter-related nature of such regimes, sometimes also main technological transformations occur which induce changes in diverse areas such as infrastructure, technology, and industrial networks. Such a transformation, commonly called a technological transition (Geels 2002), does not come about easily. It usually only occurs when a large number of actors identify them as necessary, feasible, and favorable (Berkhout 2002). Hughes (1987) showed further that it is mainly the limitation of certain technological or non-technological system components, which, if no sufficient solution can be found, triggers the emergence of a new technological regime.

\subsubsection{Measurement of technological change}

The measurement of technological change has engaged researchers for a long time. This is also reflected in the fact that one of the first reviews on this topic was already published in 1987 (see Basberg 1987). Over the years, numerous studies measuring technological change respectively transition have been published, analyzing e.g. the transition from horse-drawn carriages to modern automobiles (Geels 2005) or the technological change in the whaling industry (Basberg 1982) and the chemical industry (Lacasa et al. 2003). However, while giving us a deeper understanding of patterns of technology development, those early analyses have often been based on relatively simple measures and indicators.

In recent times, especially network-based approaches have been established as promising methods for assessing technological change, as they allow to portray technology in their generic definition: the (re)combination of existing and new technological capabilities. Regarding this, Parraguez et al. (2020) identified three different kinds of approaches for network generation, namely the usage of (1) explicit links and references between sources, (2) keywords in documents, and (3) predefined categories. 
The first group considers explicit links between documents and patents, which are provided by citations. Citations are commonly seen to provide rich information about knowledge flows and technology evolution (Jaffe and De Rassenfosse 2019). While the usability of citation data for this purpose has been discussed at length (Garfield 1955; Griliches 1979), the empirical application of the method mainly started within the last two decades (Jaffe and De Rassenfosse 2019). As one of the first, Murray (2002) looked at the co-evolutionary aspects of technological change by tracing the citation network of patent-paper pairs. In the following years, mainly two traces have been pursued, the analysis regarding scientific documents and the analysis regarding patents. While the first approach has only been used infrequently regarding the analysis of technological change (Kajikawa and Takeda 2008; Uzzi et al. 2013), especially patent citation networks established as an often-used method for analyzing technological trajectories and display related changes in technology. In this regard, an emerging amount of empirical studies involving the patent citation networks have been published regarding e.g. fuel cell technology (Verspagen 2007), printed electronics technologies (Kim et al. 2014), the electric vehicle industry (Yuan and Miyazaki 2014), wind power (Huenteler et al. 2016), and core technologies in general (Cho and Shih 2011). However, while the analysis of patent citations provides rich information especially on the importance of patents, it also has major disadvantages. In this regard, Yoon and Park (2004) mention a missing consideration of the technological-internal relationship between the patents and difficulties in grasping an overall relationship among the patents as some of the major drawbacks. This can be complemented by a missing possibility to include recent technological developments caused by missing information on their future citation.

Within the second group, technology-related keywords are used to analyze change in textual documents. Some of the most often used methods therefore are the construction of co-occurrence networks or co-word networks (Parraguez et al. 2020; Joung and Kim 2017). Within the last decade, a rising amount of related studies have been conducted, using either patent texts and abstracts (Joung and Kim 2017; Yoon and Kim 2011; Lee et al. 2008), research project descriptions (Mogoutov et al. 2008), scientific publications (Madani 2015; Chappin and Ligtvoet 2014), or a combination of these sources (most recently Parraguez et al. 2020). While the keyword approach has some main advantages, especially regarding the possibility of using multiple kinds of sources simultaneously, there are also shortcomings, which have to be considered. These include high dependence on the keyword identification method, as missing words or synonyms can lead to gaps in the used data. Further, the combination possibility of multiple sources might be limited, as there are partially large differences in e.g. structure and wording between documents (Myers 1995).

The third group relates to network creation based on predefined categories. This might be categories in bibliographies and research project databases or patent classes. Regarding bibliographies, Liu et al. (2014) used a network of disciplinary subject categories provided by the Web of Science (see Leydesdorff et al. 2013) to differentiate between research disciplines and map technological developments and changes in bioenergy research. Further studies used such methods to capture the development of new technologies such as nanotechnology (Arora et al. 2013), or also structural methods such as the analytic hierarchy process (Emrouznejad and Marra 2017). In contrast to bibliographies, patents are mostly assigned to multiple categories, which 
reflect the technological aspects of the related invention. Such international patent classification (IPC) codes provide extensive information on the composition of technology and have shown to be a good measure for technological novelty (Verhoeven et al. 2016; Fleming 2007). That is mainly because "much work on technological change agrees that the recombination of new and existing technological capabilities is one of the principal sources of technological novelty" (Strumsky et al. 2012, p.1) and patent classes exactly provide such information.

According to Dosi and Nelson (2010, p.55), "a technology can be seen as a human designed means for achieving a particular end." These means were based on pieces of procedures., knowledge, and artifacts. Thereof, we in the following conceptualize an invention according to which the building blocks are technological components reflected by IPC classes of patents. Based on Dosi (1982), "existing physical devices embody-so to speak - the achievements in the development of technology, in a defined problem-solving activity". Accordingly, technology is regarded as a system of interconnected technological components. Components are regarded as knowledge elements that are combined and therefore related. By this, we employ a network perspective, which includes nodes (knowledge/technology components) and ties (relations) (Broekel 2019; Fleming and Sorenson 2001). Thus, the relational structure of patents makes it possible to analyze the underlying knowledge as a network. We therefore assume an existing link between IPCs once they are mentioned on the same patent. Yet, as one of the few, Lee et al. (2015) used the patent classification for network creation in order to predict technological convergence patterns. However, the application of such networks for analyzing technological change has rarely been done. To fill this gap, in this paper, we use this approach and demonstrate its ability to examine patterns in technological change.

\subsection{Network structure change}

\subsubsection{Theoretical background}

Following a steady rise of network-research in the fields of economics, more recently the examination and explanation of structural aspects moved more and more into focus. Though, caused by multiple difficulties in analyzing networks, theoretical work on this topic progresses only slowly (Ozman 2009).

Regarding an actor-based network, structural network change is commonly described to be based on both changes in the number of actors due to exit or entry and changes regarding patterns in and numbers of link-formation (Koka et al. 2006). However, in the past, studies often only focused on using subsets of this definition in their examination. For example, Madhavan and Grover (1998), p.441) state that "true structural change would be evidenced by significant variation over time in the underlying pattern of relationships that bind a given set of actors" and only less regarding an increase or decrease in network activity between already existing relations. Phlippen and Riccaboni (2007) also analyzed structural change by primarily looking at the formation of new links with new partners. Such a focus on specific aspects of network change goes along with Ozman (2009, p.54), who states that "building theories to explain network structure is difficult since simplifications in their structure and focusing on relevant aspects (as determined by the context) of the network is inevitable, 
rather than covering all aspects within a unified framework." Following Strogatz (2001), reasons for such difficulties include (1) general structural complexity of networks, (2) a high diversity level regarding the nodes as well the type of ties concerning their content and weight, (3) changing states of both ties and related nodes, and (4) mutual influence between various complications.

Structural change can be seen as a basic characteristic of a network, as networks are not stable but inherently dynamic (Pittaway et al. 2004; Ebers and Grandori 1997) with "network dynamics connote[ing] the change of the network through time" (Ozman 2009, p.56). However, the network structure does not change consistently. Sometimes exogenous shocks happen which cause larger structural transformations often seen as the "real structural change" (Barley 1986; Glasmeier 1991; Phlippen and Riccaboni 2007). Such exogenous shocks are often seen in a radical technology change, as this enables peripheral actors within the network to improve their network position (Madhavan and Grover 1998). While previous studies mostly assumed a stable technology base (Phlippen and Riccaboni 2007), we can lately observe a steadily growing interest in focusing on analyzing change and evolution in highly dynamic technological areas, using diverse methods of measuring and analyzing the transformation within the related research networks.

\subsubsection{Measures of network change and network dynamics}

While in the past there have been numerous studies on network change, its drivers and other related aspects (see, e.g., Madhavan and Grover 1998; Gulati and Gargiulo 1999; Moldoveanu et al. 2003; Powell et al. 2005), literature providing information on how to precisely analyze a change in research network structure has been rather scarce. This was mainly driven by the fact that insufficient longitudinal data hindered empirical research on this topic (Ozman 2009). However, with increasing data availability in the last two decades, there has been a growing number of empirical studies relating to network structure and its transformation. The related methods and measures to analyze structural change and dynamics can be divided roughly into three categories, namely (1) the usage of network modelling or simulation tools, (2) graphical analysis, and (3) analysis via classical network indicators.

Network modelling and simulation has been mainly used for measuring network change as a function of network externalities or specific behavior of actors. The type of models used varies broadly and include e.g. agent-based simulation models (Windrum and Birchenhall 2005; Buchmann et al. 2014), evolutionary and game-theoretical models (Jackson and Wolinsky 1996; Cowan et al. 2007), or more recently exponential-family random graph models (Broekel and Bednarz 2018). The second group includes graphical analysis or the use of graph-theoretical tools for depicturing network dynamics. Regarding this, Orsenigo et al. (2001) used graph-theoretic techniques in order to analyze the influence of technological conditions on changing patterns in industry structure and evolution. However, most often authors used graphical analysis mainly as a supporting method in combination with other approaches (Roijakkers and Hagedoorn 2006; Lyu et al. 2019). The third group includes the analysis of structural change in networks based on classical network indicators. Regarding this, e.g., Madhavan and Grover (1998) measure change in the industrial network structure in the global steel industry by focusing on interblock relations and 
centrality. In their analysis of the pharmaceutical R\&D network, Phlippen and Riccaboni (2007) measure changes in the research network structure by looking at local and distant link formation by calculating the average distance between actors and the weighted clustering coefficient, respectively.

The short review illustrates a wide range of methods and approaches for getting deeper insights into network change and network evolution. However, while this previous work made important contributions to the understanding of underlying patterns and influencing factors of network transformation, it did not provide an approach for quantifying the structural change of innovation networks as a whole. Simulation and modelling approaches are primarily focused on identifying relevant drivers or barriers to network dynamics but do not directly determine to what extent a network alters. Graphical representations have the advantage of providing a vivid depiction of network configuration allowing us to identify similar or divergent patterns between networks. However, they do not give us quantitative information on the structural change and therefore make it difficult to compare the change between e.g. different network configurations. While the use of classical network indicators provides such quantitative information, they rather aim to outline specific patterns of network structure (Bodin 2006) and their development but fail in describing network change as a whole. To sum up, there is currently no measure for investigating overall structural change regarding research networks. To fill this gap, in the following, we are going to describe a possible approach for measurement of network structure transformation and illustrate its functionality.

\subsection{Co-evolution of research networks and technology}

In general, the literature assumes that technology and research networks do not evolve by themselves, but rather co-evolve (Phlippen and Riccaboni 2007; Murray 2002). However, there are two directions to view the relationship between the structural change in a research network and technological change. The first is that technological change induces a change in the research network. The second is that conversely technological change is induced by a changed research network structure. In a more general way, these directions have already been shown by Burkhardt and Brass (1990, p.104) who pointed out that the relationship between structure and technology or more specifically the questions "Does technology drive structure? Or does technology adapt to existing structure, reinforcing established, stable patterns?" has been discussed for a long time.

In this regard, the first possible direction states that technological change leads to a change in the research network. This seems especially to be the case for radical technological changes, which have an important influence on the network structure in fields of high technology (Anderson and Tushman 1990). Madhavan and Grover (1998) show that specific events, like a radical change in technology, potentially change the basis of competition and therefore provide the occasions for the restructuring of an existing network. Phlippen and Riccaboni (2007) also confirmed this when studying the establishment of a new technological paradigm in the biopharmaceutical industry. They found that a technological transition, which was induced by a radical innovation, led to a significant structural change in the network represented by numerous firm entries and the formation of numerous new alliances. Furthermore, they 
discovered that established actors tended to leave existing connections and collaborations and instead intensified networking with new partners. The second direction considers that, conversely, technological change is induced by a changed research network structure. This is through the formation of new alliances, which allows facilitating new knowledge flows between the alliance members (Gomes-Casseres 2006) and thereby enhances their innovativeness (Deeds and Hill 1996). Such an increase in innovative performance also holds true if the network connection is only indirect (Owen-Smith and Powell 2004; Ahuja 2000).

Despite the concept of coevolution constitutes an important part of economics as well as the sociology of technological change (Rosenberg 1982), there are only a few empirical studies dealing with the co-evolution of technology and research networks. Murray (2002) explored the co-evolution of scientific and technological networks on the example of tissue engineering. The study of Blankenberg and Buenstorf (2016) investigated the co-evolution between innovation and public research for the German laser industry, and van der Pol and Rameshkoumar (2018) investigated the co-evolution between knowledge and collaboration networks along a technology life-cycle. Though, studies so far did barely investigate the co-evolution regarding technological sectors undergoing a change in its technological regime. Further, there has yet no consistent indicator been used to make the two evolutionary processes comparable.

\subsection{The regime change in the German automotive innovation system}

We base our analysis on the German automotive sector, which is currently fundamentally challenged by the technological shift towards battery electric vehicles (BEV). By combining technologies of different fields, such as classical car manufacturing, battery technology, and electric engine technology, electric vehicles not only break the established production and coordination processes but also change the relevant knowledge necessary in vehicle production. Especially when looking at the automobile sector, a new technological trajectory of electrically propelled cars is steadily emerging. While such new trajectories mostly are characterized by high uncertainty of success (Dosi 1982), the success probability in the case of innovative electric vehicles seems to be quite high. This is mainly because they benefit from various political, economic, ecologic, and social factors, such as stricter carbon emission rules, rising oil prices, and a change in the general mobility behavior with new tendencies to intermodality and car-sharing, which are expected to have even more importance in the future (Dijk et al. 2013). Therefore, the current development in this area might be seen as the start of a change regarding the technological paradigm (Dosi 1982), which especially established car producers cannot ignore. For them, this new paradigm poses a high risk as it, at least in the medium-term, endangers their core competencies such as the manufacturing of internal combustion engines (ICE). For the "new" actors in the field of battery technology and electric engines, on the other hand, the new technology can more be seen as an opportunity, as their production fields are not endangered but rather expandable to the new application area. The current German automotive sector is therefore excellently suitable for examining both the transformation of research networks and technological change in general. 


\section{Data}

\subsection{Research network data}

In order to map the German research network within the field of vehicle technology, we took into account publicly funded research projects from national and international project funding registers. These databases provide numerous information on all funded research projects and involved actors respectively. The main information source for cooperation projects in Germany is the German national funding catalog ${ }^{1}$, listing all publicly funded research projects by the federal republic including the participants, the project duration, the research area, and a description of the project. The database was searched by projects in the field of automotive engineering and management regarding both conventional and electric vehicles. This was done by identifying relevant research area IDs, shown in Table 1. Besides projects in the field of automotive engineering and management, also relevant projects in the area of vehicle-related battery technology were included in the search. Within this area, the database of the German battery forum ${ }^{2}$ was used, containing information on all electric vehicle-related battery research projects.

By use of the database of the Community Research and Development Information Service (CORDIS), run by the European Commission, also EU-projects were taken into account for network creation. However, as the focus of this study is on the German research network, only the German participants have been considered for the final network and only if there are two or more within a project. In order to retrieve the relevant information, we used data and text mining methods due to a lack of sufficient export possibilities. The extensive database was searched by multiple keywords regarding automotive engineering and battery technology, filtered by German participants, and afterward manually checked for relevance.

Once the data collection was accomplished, the information was joined and postprocessed. This includes the unification of the names from the actors found as well as the removal of duplicates. In total, the final network consists of 720 actors connected through 6238 edges in the period 1993 and 2016.

Based on the collected information, we can create a network between the identified actors, which are connected to each other via the different research projects. We therefore denote this network in the following as research network. Further, we assume that the actors within this network pursue research goals, as research is the main aim of governmental funded research projects. The process of data acquisition and network creation is depicted in Annex 1.

\subsection{Technology data}

To analyze technological change, information from vehicle-related German patents was retrieved using the OECD PATSTAT database. In order to isolate relevant applications, we used the International Patent Classification (IPC) as well as the Cooperative Patent Classification (CPC), whose codes provide information about the technology classes of

\footnotetext{
${ }^{1}$ Also called "Förderkatalog," access via https://foerderportal.bund.de/foekat/jsp/SucheAction.do? actionMode=searchmask (in German language)

${ }^{2}$ https://www.batterieforum-deutschland.de/ (in German language)
} 
Table 1 Relevant project areas

\begin{tabular}{ll}
$\begin{array}{l}\text { Research } \\
\text { area ID }\end{array}$ & Description \\
\hline GC3020 & $\begin{array}{r}\text { Complete electric vehicle system (with focus on vehicle } \\
\text { electronics and energy management, vehicle conception, and manufacturing processes) }\end{array}$ \\
HA8050 & $\begin{array}{l}\text { Vehicle integration of electric powertrains, drive management, integration into security system } \\
\text { EB1850 }\end{array}$ \\
MC3050 & Vehility in general electronics \\
\hline
\end{tabular}

the patents. A patent classification code consists of both a main technology class and several hierarchical-related subclasses, allowing a fine assignment of the patent to technological areas (Strumsky et al. 2012).

For patent identification, relevant codes were retrieved from literature (see, i.e., Borgstedt et al. 2017; Pilkington and Dyerson 2006) as well as from a manual search within the Patent Classification database. The results include classes within the categories of motor technology, motor controlling technology, combustion engines, engine control systems, battery technology, battery management, and electric vehicle controlling systems, shown in Table 2. Based on the identified classes, we searched for associated patents with German origin in the PATSTAT database. By referring to only one patent per patent family, we take into account that some patents have been registered in different patent offices and therefore avoid a double counting of the same invention.

In order to get information on the technological composition, all related classification codes were extracted from the identified patents. Usually, a patent is assigned to more than one classification code, allowing us to identify the different technological areas associated with the invention. For analysis, we decided to use the codes on the 4th level (main group) as illustrated in Fig. 1. This level provides a sufficient technological depth to easily divide different technological areas and simultaneously allows us to aggregate lower subgroup levels with high technological relatedness to each other. Further, it reduces the computational burden for the following analysis, as there are currently more than 70.000 different IPC codes on the lowest level. As a result of the data collection, we received 1259 technology classes related to 13,585 relevant vehicle patents.

Based on the collected patent data, we can create a network between the different IPC resp. CPC classes, which are connected to each other via the patents they are assigned to. We therefore denote this network in the following as technology network, which gives information on the used combinations between technological components. The process of data acquisition and network creation is depicted in Annex 2.

\section{Method}

\subsection{Measuring network change}

For measuring the overall change inside a network, we use the RV coefficient introduced by Escoufier (1970, 1973) and Robert and Escoufier (1976) as one of the multiple existing 
Table 2 Relevant patent categories

\begin{tabular}{|c|c|c|}
\hline Patent category & $\mathrm{IPC} / \mathrm{CPC}$ & Patent-classes considered \\
\hline \multirow[t]{2}{*}{ Battery technology } & IPC & H01M 4/13, H01M 6/14, H01M 6/16, H01M 10/52\%, H01M 10/48 \\
\hline & $\mathrm{CPC}$ & Y02E 60/122, Y02E 60/124, Y02E 60/128, Y02T 10/7011 \\
\hline \multirow[t]{2}{*}{ Battery management } & IPC & B60L 3/\%, B60R 16/04, B60S 5/06, G01R 31/36 \\
\hline & $\mathrm{CPC}$ & $\begin{array}{l}\text { B60L 2240/545, B60L 3/\%, H01M 10/486, H01M 10/5004, H01M } \\
\text { 10/5008, H01M 10/5022, H01M 10/503, H01M 10/504, H01M } \\
\text { 10/5059, H01M 10/5075, Y02T 10/7022, Y02T 10/7044, Y02T } \\
\text { 10/7077, Y02T 90/14, Y02T 90/16, Y02T 90/163 }\end{array}$ \\
\hline \multirow[t]{2}{*}{ Motor technology } & IPC & $\begin{array}{l}\text { B60L 11/\%, B60L 15/\%, B60L 9/\%, B60L 11/18\%, } \\
\text { H02K 017\%, H02K 041 }\end{array}$ \\
\hline & $\mathrm{CPC}$ & $\begin{array}{l}\text { B60L 11/02, B60L 11/04, B60L 11/06, B60L 11/08, } \\
\text { B60L 11/10, B60L 11/12\%, B60L 11/18\%, Y02T 10/621\%, Y02T } \\
\text { 10/622\%, Y02T 10/623\%, Y02T 10/624\%, Y02T 10/625\%, Y02T } \\
\text { 10/626\%, Y02T 10/627\%, Y10S 903/00, Y10S 903/902, Y10S } \\
\text { 903/903, Y10S 903/904, Y10S 903/905, Y10S 903/906, } \\
\text { Y10S 903/907, Y10S 903/91\% }\end{array}$ \\
\hline $\begin{array}{l}\text { Motor controlling } \\
\text { technology }\end{array}$ & IPC & $\begin{array}{l}\text { H02P 1/\%, H02P 3/\%, H02P 5/\%, H02P 6/\%, H02P } 7 / \%, \\
\text { H02P 9/\%, H02P 21/\%, H02P 23/\%, H02P 25/\%, H02P 27/\%, H02P } \\
\text { 29/\%, H02P 31/\% }\end{array}$ \\
\hline \multirow[t]{2}{*}{$\begin{array}{l}\text { Electric vehicle } \\
\text { controlling systems }\end{array}$} & IPC & $\begin{array}{l}\text { B60K 6/2\%, B60K 6/3\%, B60K 6/4\%, B60K 6/5\%, } \\
\text { B60L 15/\%, B60L 1/\%, B60L 5/\%, B60L 8/\%, B60W 10/26\%, } \\
\text { B60W 20/\%, B60W 10/28, H01M 10/44, H02J 7/\% }\end{array}$ \\
\hline & $\mathrm{CPC}$ & $\begin{array}{l}\text { B60K 2001\%, B60K 1/00\%, B60K 1/04\%, B60K 2006/262\%, B60K } \\
\text { 2006/264\%, B60K 2006/266\%, B60K 2006/268\%, B60K } \\
\text { 2006/48\%, B60K 6/2\%, B60K 6/4\%, B60L 5/\%, B60L 8/\%, B60W } \\
\text { 20/\%, Y02T 10/705, Y02T 10/7055, Y02T 10/706\%, Y02T } \\
\text { 10/7061, Y02T 10/72\% }\end{array}$ \\
\hline Combustion engines & IPC & $\begin{array}{l}\mathrm{F} 02 \mathrm{~B} \%, \mathrm{~F} 02 \mathrm{D} \%, \mathrm{~F} 02 \mathrm{~F} \%, \mathrm{~F} 02 \mathrm{M} \%, \mathrm{~F} 02 \mathrm{~N} \% \text { (narrowed down by } \\
\text { vehicle-related keywords) }\end{array}$ \\
\hline
\end{tabular}

algorithms for calculating matrix correlation (see Josse and Holmes 2016). The coefficient aims at measuring the relationship between two variable sets and is widely used in ecology (Klingenberg 2009; Gangopadhyay et al. 2001), sensory analysis (Tomic et al. 2013; Niu and Varshney 2007), and neuroscience (Zhang et al. 2009). It is also often referred to as being the most appropriate relating to measuring the similarity of squared and symmetric matrices (Josse et al. 2008; Smilde et al. 2009).

The RV coefficient bases on the principle that there is a perfect correlation between two variable sets if an orthogonal transformation exists that makes the two sets corresponding to each other. With (1) $X$ being a $n \times p$ matrix with $p$ variables of $X_{1}$ to $X_{p}$, (2) $Y$ being a $n \times q$ matrix with $q$ variables of $Y_{1}$ to $Y_{q}$, and (3) both sets being

\begin{tabular}{|c|c|c|c|c|}
\hline A & 01 & $B$ & $33 / 00$ & $\begin{array}{l}\text { Main group }-4^{\text {th }} \\
\text { level }\end{array}$ \\
\hline \multirow[t]{3}{*}{ Section $-1^{\text {st }}$ level } & & \multirow{4}{*}{$\begin{array}{l}\text { Subclass }-3^{\text {rd }} \\
\text { level }\end{array}$} & \multirow{3}{*}{$\begin{array}{l}\text { or } \\
33 / 08\end{array}$} & \multirow{4}{*}{$\begin{array}{l}\text { Subgroup - lower } \\
\text { level }\end{array}$} \\
\hline & Class $-2^{\text {nd }}$ level & & & \\
\hline & & & & \\
\hline & & & Group & \\
\hline
\end{tabular}

Fig. 1 Structure of patent classification codes (figure based on WIPO 2019) 
defined for the same $n$ individuals and centered by columns, the RV coefficient can be defined as:

$$
\operatorname{RV}(X, Y)=\frac{\operatorname{tr}\left(X X^{\prime} Y Y^{\prime}\right)}{\sqrt{\operatorname{tr}\left(\left(X X^{\prime}\right)^{2}\right) \operatorname{tr}\left(\left(Y Y^{\prime}\right)^{2}\right)}}=\frac{\operatorname{tr}\left(S_{X Y} S_{Y X}\right)}{\sqrt{\operatorname{tr}\left(S_{X X}^{2}\right) * \operatorname{tr}\left(S_{Y Y}^{2}\right)}}
$$

At this, with tr being the trace-operator, $S_{X X}=\left(\frac{1}{n-1}\right) X^{\prime} X$ and $S_{Y Y}=\left(\frac{1}{n-1}\right) Y^{\prime} Y$ refer to the respective empirical covariance matrix and $S_{X Y}=\left(\frac{1}{n-1}\right) X^{\prime} Y$ respective $S_{Y X}=\left(\frac{1}{n-1}\right)$ $Y^{\prime} X$ refer to the empirical covariance matrix between $X$ and $Y$. The coefficient itself lies between zero and one with one indicating a perfect similarity between the matrices and zero a complete dissimilarity.

The respective procedure applied for both networks is illustrated in Fig. 2. It is based on a similar procedure used by Parraguez et al. (2020) who used the basic RV coefficient to quantify technological change based on terms in documents. However, the underlying network conception, used data sources, and the application field in the present paper vary considerably.

For analyzing the change within the research network, we start by creating edgelists, which represent the cooperation behavior of the different agents, consisting of companies, research institutions, and universities, for each year. Two agents are connected if they share at least one research project in the respective year. However, multiple connections of the same actors through different projects are also considered. Based

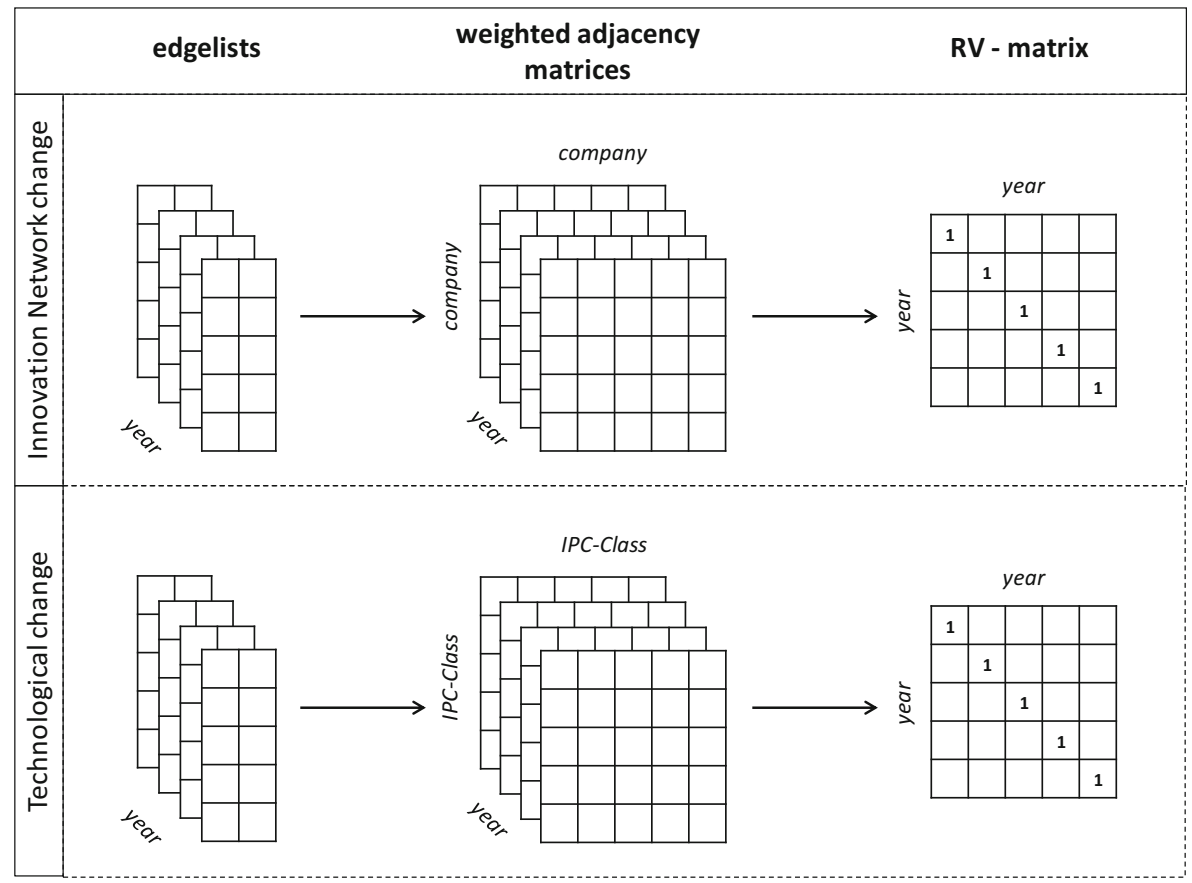

Fig. 2 Schematic overview over the RV matrix generation procedure. Own representation based on Parraguez et al. (2020) 
on the created lists, we calculate corresponding weighted adjacency matrices, which illustrate the cooperation networks and the respective cooperation intensity between actors. Afterward, we apply the RV coefficient to all possible pairs of matrices in order to obtain a similarity matrix of the network between the years. This allows us on the one hand to compare the similarity of the network structure between the different years and on the other hand a matching of consecutive years to identify breaks within the network development. The same procedure is used for analyzing the change in technology. However, the edgelist in this case is based on the different patent classification codes, which are connected to each other by the patents they are assigned to. Highly weighted values within an adjacency matrix therefore indicate a set of technological categories often combined in patents of the respective year. Conversely, a value of zero indicates a combination of technology categories that have not been applied in any patent. After calculating the RV values between the different adjacency matrices, the calculated RV matrix gives us information on how similar the combinations of technological areas were between the years. This further allows us to identify times of major changes in technological composition as well as periods of technological stability.

\subsection{Identifying relations between research network change and technological change}

For identifying the relatedness of the change in the research network and the technological change, we use a cross-correlation function methodology. This method is especially useful, as it can be expected that major changes in the two networks, as far as they show similar patterns at all, do not occur simultaneously but rather shifted in time.

The use of the cross-correlation function became very popular since the works of Simkin (1974) and Tonry and Davis (1979) and has been commonly used in signal and communication system analysis since. The function measures the similarity of two different processes when one of them is shifted in time relative to the other. It can therefore be seen as a generalized version of a linear correlation, which compares two time series $x(t)$ and $y(t)$ to see if they match and with which shift in time the best match occurs. The standard cross-correlation can be depicted as follows:

$$
R_{x y}\left(t_{1}, t_{2}\right)=E\left\{X\left(t_{1}\right) * Y\left(t_{2}\right)\right\} \quad \text { with } \quad x \neq y
$$

For analysis, we can easily create the needed time series out of the calculated RV matrices. Relating to the change between two consecutive periods of time $t-1$ and $t$, the degree of change can be depicted as

$$
\mathrm{RV}_{t t}-\mathrm{RV}_{t t_{-1}}=1-\mathrm{RV}_{t t_{-1}}=1-\mathrm{RV}_{t_{-1} t}
$$

with $\mathrm{RV}_{t t}$ being the RV value from year $t$ and year $t$, which is always one, and $R V_{t t_{-1}}$ being the RV value from year $t$ and year $t-1$.

\section{Results and discussion}

The calculated RV graph for the technology network based on patent class combinations is depicted in Fig. 3. The matrix on the left shows us the correlation between the 


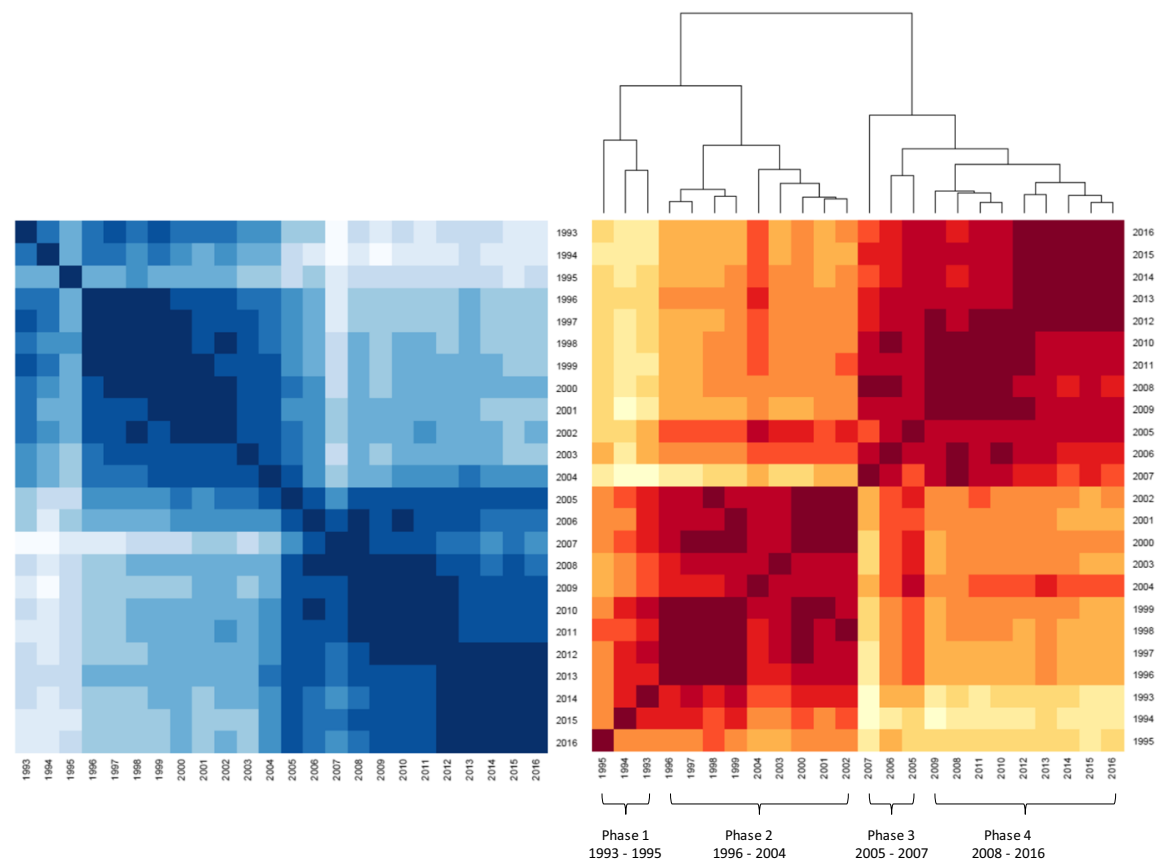

Fig. 3 RV matrices for the patent class network with development in ascending order (left) and clustered by similar years (right)

network structure in different years in ascending order. Values range from zero (white) to one (dark blue), with the diagonal line showing a perfect correlation, as the correlation of a network structure with itself is always 1 . Originating from this diagonal line, we can observe phases of network stability, apparent as larger blocks of darker color. Further, also main network changes can be identified graphically as the years where larger blocks of stability adjoin each other. To get a better overview over years with a similar structure, we also performed a hierarchical clustering procedure on the matrix based on the clustering process provided by Johnson (1967). The results are shown in the right matrix of Fig. 3: the darker the red, the higher the correlation between the years.

Regarding the technological change, we can observe two main clusters of years with similar patterns in technology composition as well as two minor phases with fewer similarities. For each, Table 3 gives us an overview of the top eight technology class combinations during the covered phase. Looking at the first phase, ranging from 1993 to 1995 , we can identify combinations of conventional vehicle-related patent classes as main parts of the network structure, followed by combinations of conventional and hybrid/electric vehicle classes. This indicates that the main technological development was still mainly driven by enhancing classical combustion-engine-driven vehicles, although alternative vehicle technology was already relevant. During the second phase between 1996 and 2004, the relevance of electric vehicle technology knowledge steadily increases. However, especially combinations of electric and classical vehicle classes dominate patenting during this time, indicating a main focus on hybrid electric vehicles. This is also confirmed by the German Patent and Trade Mark Office, which 


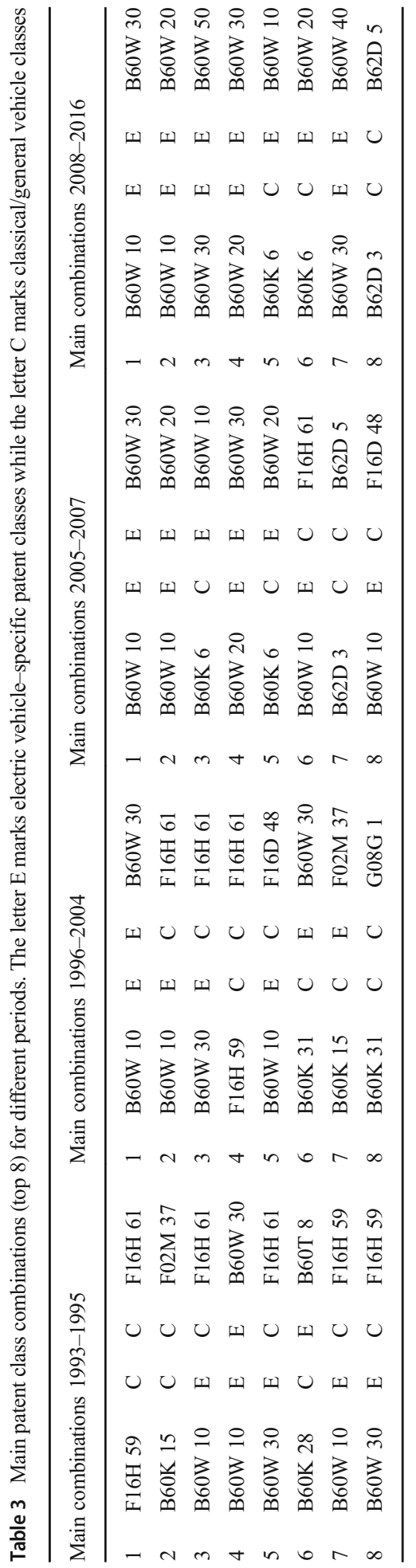


identifies especially hybrid cars as the main technological focus of these years (GPTO 2007). The third phase ranges from 2005 to 2007 and shows similarities to the previous as well as the following cluster. It can therefore be seen as a short transition period before the establishment of the so far last large stable cluster between 2008 and 2016. According to the main patent combinations of this time, a clear focus to base new patents on the combination of electric vehicle-related technologies becomes visible. By interpreting the results, we need to be aware that the technological change is related to the individual decision of the different actors on patenting. However, as the indicator refers to the composition of all existing automotive patents of German origin (in the respective time), it can be seen as detached from individual firm strategies and rather depicts the general change in technology.

The different phases of technological transformation also become visible in Fig. 4, which shows the correlation for the different years with the prior and following years. Periods of high similarity are highlighted by the same color. With a look at the courses shown, it becomes apparent that especially the two larger periods 2 and 4 do not only show high similarity between the respective years but the years of each cluster also show similar correlation patterns to the times before and afterward. This is not the case for the third phase, which can be identified as highly unstable with highly diverse correlation patterns of its years. Especially the year 2007 represents a significant structural break regarding the composition of technology.

Within the research network depicted in Fig. 5, we can see a high fluctuation in correlation. In contrast to the technology network, the research network looks far less stable across the years. This can notably be explained by the research networks being based on research projects which are characterized by a high amount of varying actors in the diverse federal research projects. However, also in the research network, phases of stability and stronger network change are visible.

As the research network is based on governmental funded cooperation projects, the patterns in network development, as well as the thematic focus, are highly driven by decisions of state representatives respectively representatives of the European

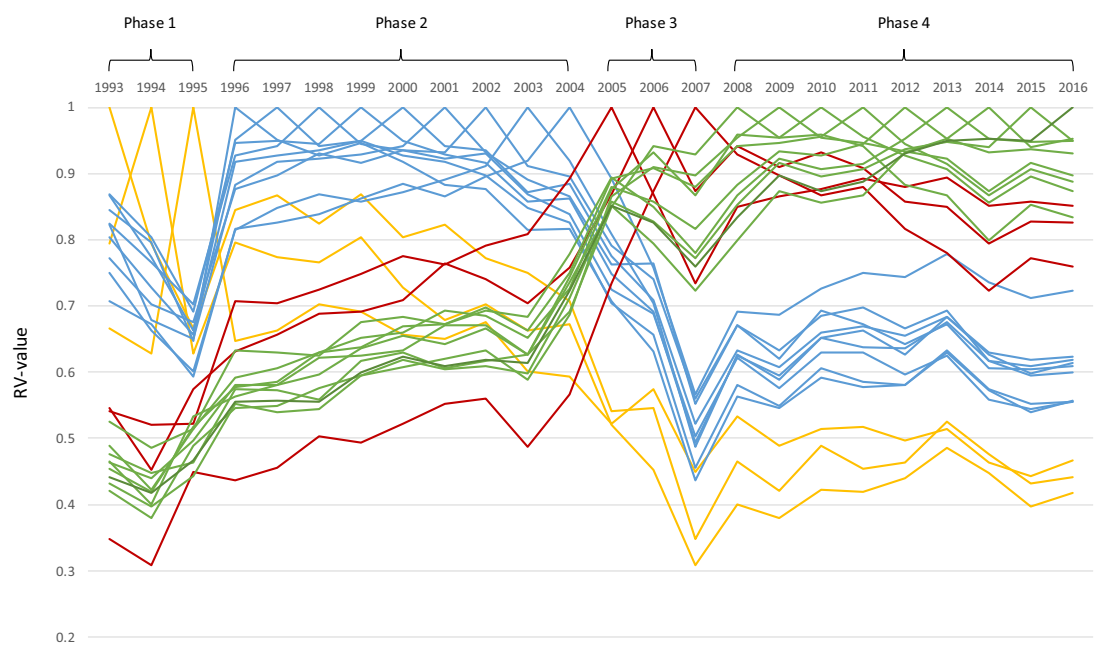

Fig. 4 Correlation between different years regarding technological composition of patents 


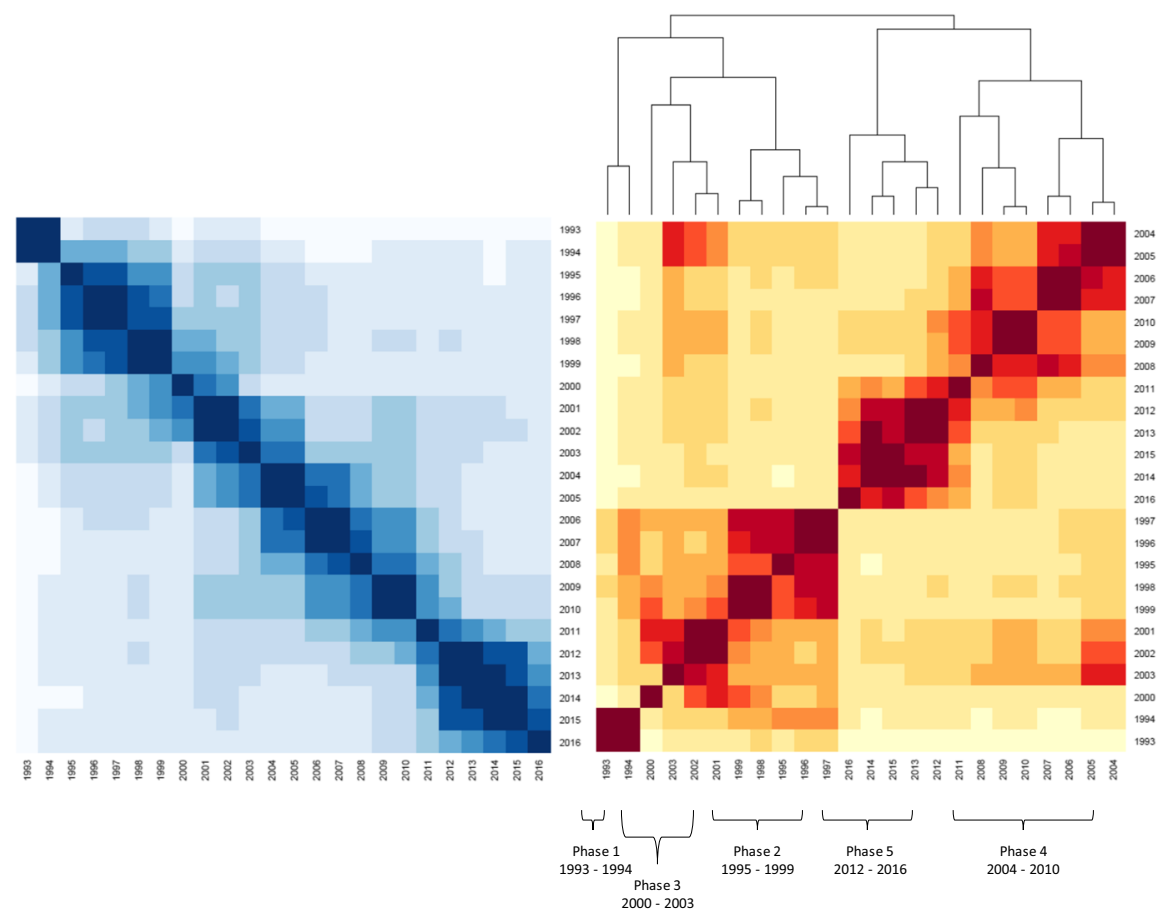

Fig. 5 RV matrices for the German vehicle research network with development in ascending order (left) and clustered by similar years (right)

Commission. The results should therefore be interpreted under consideration of the specific patterns related to such publicly funded programs, like a pre-planning of the funding direction in periodic research programs (mostly every 2 to 4 years) and the influence of the political agenda of the governing parties. We can identify four main phases of network stability between the years 1993 and 2016. The first small cluster covers the years 1993 and 1994 and falls together with intensive governmental funding programs of research related to vehicle efficiency and safety. Cluster two as the first larger period of network stability correlates very well with the periods of two extensive research programs of the federal government, which show thematic similarities. Both programs, ranging from 1996 to 1999 and 2000 to 2003, focus on funding research regarding vehicle noise reduction, vehicle-related safety, and security as well as the reduction of vehicle-related climate gases (BMBF 1996, 2000). Especially the latter, at least partly, anticipated the main funding topics of the following years, which set thematic emphasis in alternative vehicle drive trains and hybrid vehicles (BMBF 2004, 2008, 2010). Within the years 2009 to 2010, also the second German economic stimulus package was approved, reinforcing the funding of new technology developments regarding hybrid vehicles and storage technology. This thematic shift to alternative drive trains coincides quite well with the third large network stability cluster from 2004 to 2010. In the following years, an even deeper focus on fully electric vehicle technology was envisaged, expressed in the government program electric mobility in spring 2011 (BMWi 2011). This focus was maintained until the end of the investigated period and contained i.e. the investment of 1.5 billion euros until 2014 
with an emphasis on R\&D funding for establishing Germany as a lead market in electric mobility (BMBF 2014, 2016). The funding focus was largely in line with the funding focus of the European Commission, which launched their "European Green Cars Initiative" in 2009 and continued it in 2013 as the "European Green Cars Initiative" with the main target on the development of components for electric vehicles.

Figure 6 provides an alternative view of the correlation between the different years. In comparison with the respective graph of the technological change, both a higher instability inside the phases and a much sharper decline in correlation between the phases become visible. This coincides with a substantial alteration of the network structure during the regime change. This is for instance illustrated by the network structure of the first observed years 1993/1994 having an RV value of only between 0.2 and 0.25 during the end of the observation period.

Figure 7 shows the transformation of the vehicle technology in German patenting with the transformation of the German research network. The graph cumulates the RV values for each year and its predecessors and normalizes it by the cumulated RV values across the whole time period. For both courses, the main stable phases and their respective focuses are marked, allowing us to identify co-evolutionary processes. Within the first observed years, the thematic focus of both processes seems equal, with patents mainly consisting of a recombination of classical vehicle technologies and research focus on general vehicle safety. However, between 1994 and 1996 the vehiclerelated patents experienced a sharp shift in technological composition. This marks the start of the transition between classical combustion engine-based vehicle patents and hybrid electric vehicle-based patents whose number steadily expands during the following nine years until 2005. During this time, the research network at first still concentrates on research regarding cleaner combustion engines followed by an extension by hybrid electric vehicle (HEV) and battery electric vehicle (BEV) concepts in 2000. This phase passes to a longer time of more concretized research regarding hybrid electric vehicles from 2004 to 2010. However, one year later, the patent trend of hybrid

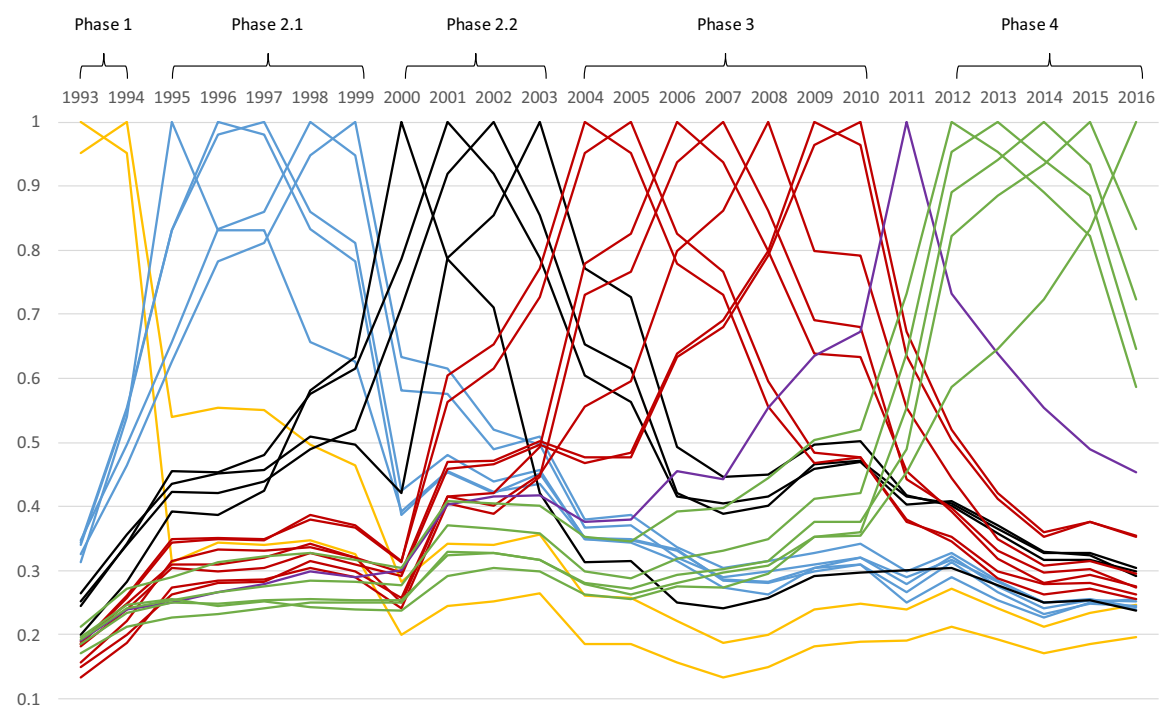

Fig. 6 Correlation between different years regarding the structure of the research network 


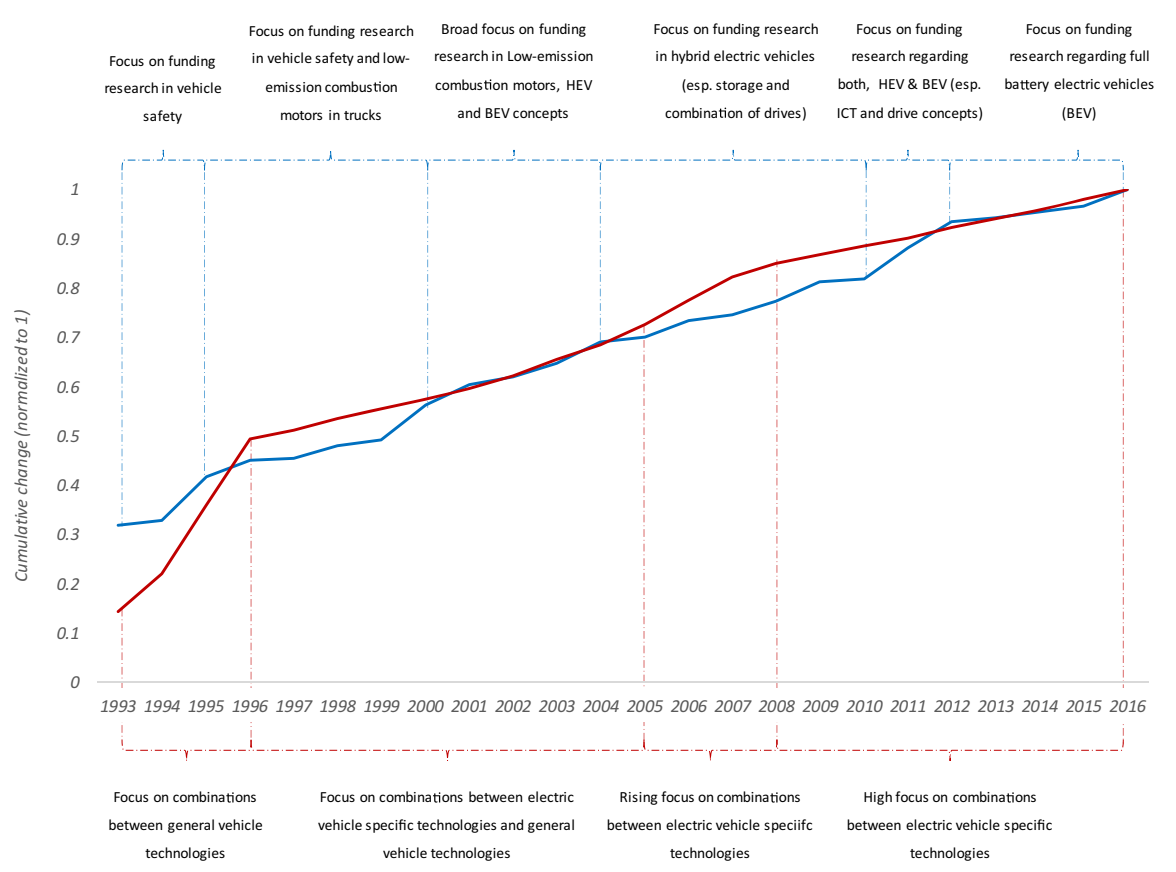

Fig. 7 Co-evolution of the technology network (red) and the German research network (blue)

electric vehicle technology composition already starts shifting in a growing trend to combine only electric vehicle-related technologies, leading to a lasting stable phase with a focus on electric vehicle technology from 2008 to the end of the observation in 2016. The shifting phase from HEV to BEV in the German research network is observable at first in 2010, lagging about 4 to 5 years behind the technological networks period of shift. The same becomes observable regarding the establishment of a stable battery electric vehicle research pattern in 2012, which was already realized years earlier in the technology network.

The co-evolutionary process shown in Fig. 7 confirms the results of Madhavan and Grover (1998) and Phlippen and Riccaboni (2007), who state that especially in the case of radical change and the emergence of a new technological regime technology leads to the restructuring of existing networks. This might be explained by governmental funding focusing on the further development of currently promising technologies, which have at least a certain degree of maturity. Also, many governmental R\&D projects aim at improving the commercialization of new technologies and therefore base on previous basic technological research. This reduces the risk and allows concentrating on the development of relevant aspects for a later diffusion. However, we also have to keep in mind that funding mostly bases on prefixed funding programs and therefore is only partially dynamic. Hereby such programs might only be adjusted in a 2- to 4-year period and therefore almost compulsorily have to follow main technological developments.

The lag of the research network can also be confirmed by the results of the crosscorrelation function. Here the autocorrelation between the two courses of time, depicted in Fig. 8, shows an at least slightly significant general lag of 5 years, which is consistent with some of the findings in Fig. 7. The positive expression of the autocorrelation factor 


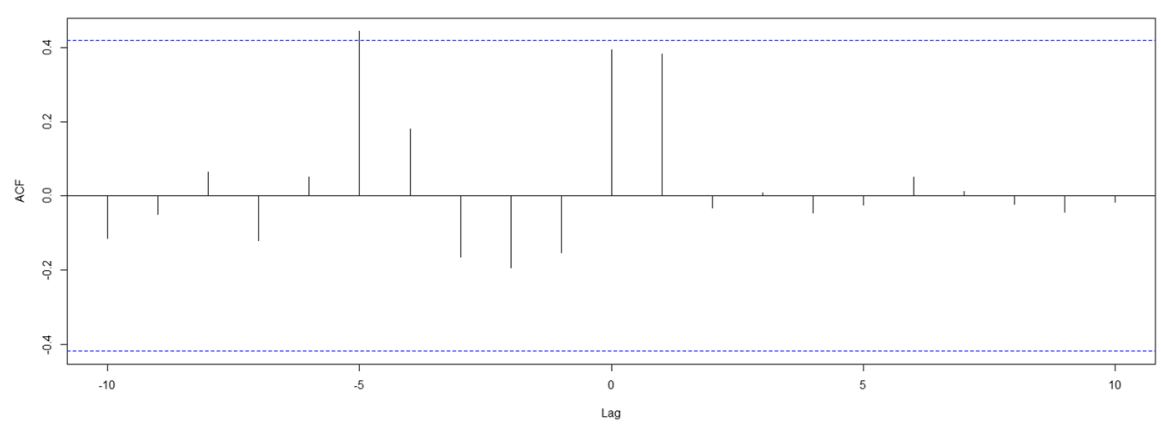

Fig. 8 Cross correlation between technology change and structural change in the research network

means that a higher change in the technology network leads to a higher change in the research network. Therefore, we can anticipate that this is the approximate reaction time of the research network transformation to the start of main changes in technology composition, at least in the field of vehicle technology. ${ }^{3}$

However, the results do not necessarily conflict with the positive relationship between (governmental) subsidy and R\&D effort, which has been previously found (Hall et al. 2009). Rather, the German automotive sector might represent a highly special case, as it has a high focus on R\&D investments. In this regard, the German automotive industry alone spent almost 39 billion euros on R\&D in 2016, which is about $40 \%$ of all German expenditures in research and development this year (Bormann et al. 2018). As by this the German automotive industry is commonly seen as one of the most innovative industries (Hofbauer and Sangl 2019), governmental funding of the generation of automotive innovations seems less necessary than funding projects related to tests and diffusion of already existing promising technologies.

Additionally, Mikler and Harrison (2012) find that in sectors with a high political coordination between both private sector and government, states tend to pursue longterm visions regarding technology, which are in line with the interests of the incumbent actors. This is the case for the internal combustion technology respectively diesel technology in Germany, where the stability of policy ensures a long-term policy support for the development of technologies (Meckling and Nahm 2018). Such a long-term policy might result in a delayed funding of research in hybrid and electric vehicle technology as it cannibalizes the existing regime.

\section{Conclusion}

In the present paper, we analyzed development patterns in technology and research network formation as well as their co-evolution by a network-based

\footnotetext{
${ }^{3}$ There are also some higher but insignificant autocorrelation factors for both a simultaneous development without any lag and a lag of one year regarding the technological change. These are also observable in Fig. 7 but are inconsistent regarding the match of the respective focuses at these times.
} 
approach. Our results show that the applied procedure is particularly useful for identifying development patterns and in both research networks and technology networks. It further offers the possibility to compare the transformation of different networks with each other.

Regarding the analysis of the technological development in the vehicle sector, we can identify different phases of high stability in patent composition, which can be assigned to certain invention foci. Based on this, a clear trajectory in technological development from classic combustion-engine-based vehicles over hybrid electric vehicles to battery electric vehicles can be identified. The German automotive research network shows similar phases. However, the research network is quite unstable in its composition, caused by steadily changing actors and research projects. Further, while the general development process is mainly similar to the technology network, phases do not occur simultaneously but rather shifted in time. The co-evolution between the two processes indicates that, regarding the German automotive sector, changes in technology lead to structural changes in the government-funded research network. Following the results, a shift of approximate 5 years between the main changes in technological composition and research network structure can be identified.

The present paper complements the evolving literature regarding the measurement of technological change and research network dynamics as well as coevolutionary processes in research and technology. Especially the used approach might also be relevant for policy decision-making in several respects: It, on the one hand, provides an instrument to analyze the government-funded research network regarding its development, stability, and structural changes as a whole. On the other hand, it allows retracing processes of technological change in order to identify possible technological trends at an early stage and to better align innovation management decisions thereto.

There are some limitations in our analysis we need to mention. These are on the one hand data limitations. In our analysis, we use research project data from the German national funding database and the CORDIS database of the European Commission. However, while the extracted information gives us a comprehensive overview of collaboration in publicly subsidized research, we need to be aware that it covers only a part of research cooperation. For further research, it might be interesting to also take a look at sources besides governmental funded cooperation projects, such as papers and other publications. Another limitation relates to the used methodology. There are further matrix correlation measures as e.g. the dCov measure (Josse and Holmes 2016) which might also be useful to quantify network change. However, a comparison between different correlation measures is beyond the scope of this paper and might be an interesting topic for future research. Moreover, as a further research issue, we intend to have a closer look at the institutional factors and the role of government that might to some extent drive the formation of certain network structures in the case of funded collaborative research. On the one hand, there can be stipulations that require partnering with a certain type of organization (e.g., SME) or with regard to the number of actors involved. On the other hand, actors are free to choose R\&D partners that are most valuable for them (e.g., with respect to their absorptive capacity). 


\section{Annex 1. Research network}

\section{Project search procedure}

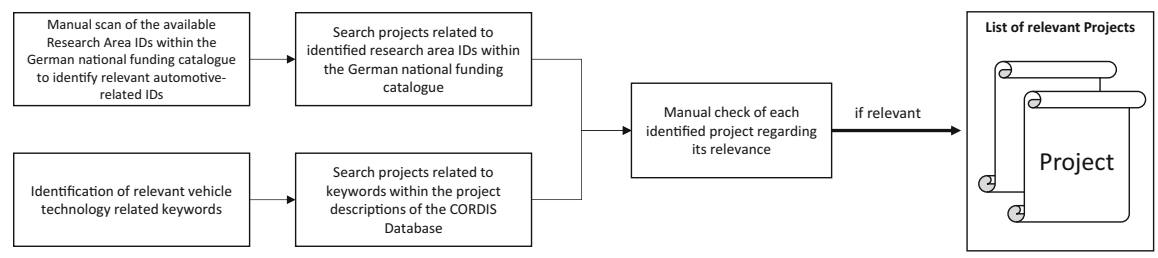

Fig. 9 Schematic depiction of the project search procedure

\section{Network generation procedure}

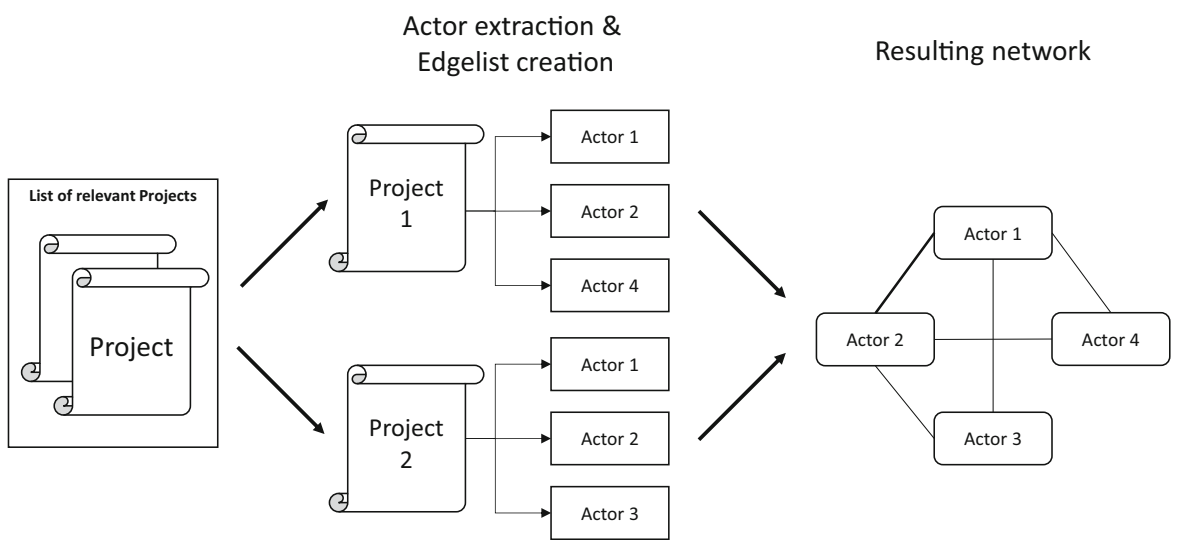

Fig. 10 Schematic depiction of the research network generation procedure

\section{Annex 2. Technology network}

\section{Patent search procedure}

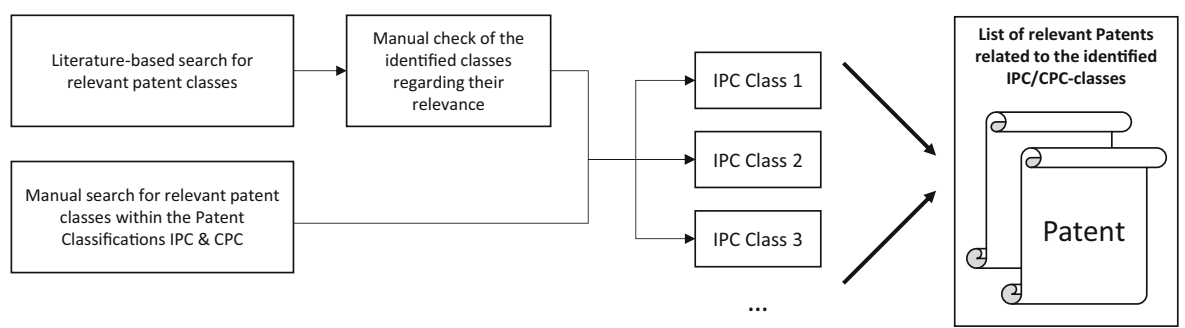

Fig. 11 Schematic depiction of the patent search procedure 


\section{Network generation procedure}

CPC/IPC-Class extraction \&

Edgelist creation

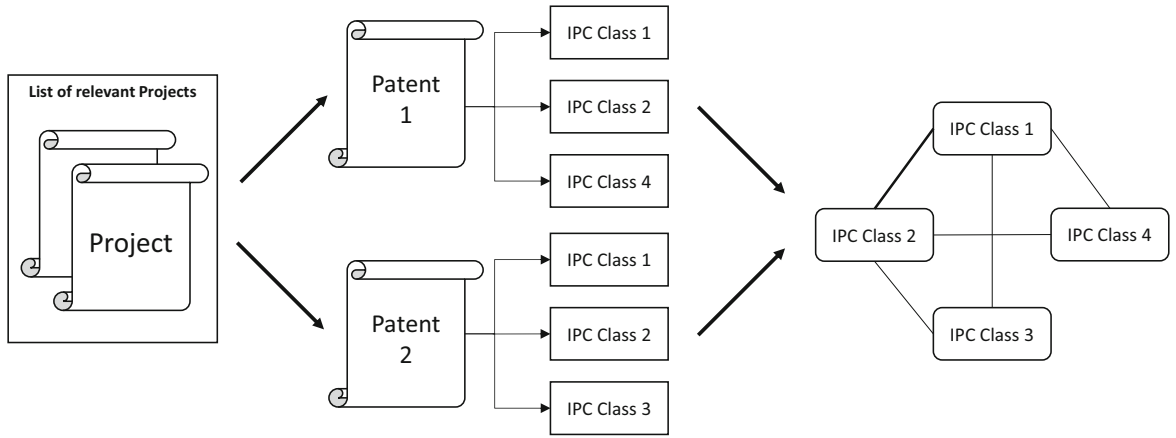

Fig. 12 Schematic depiction of the technology network generation procedure

Funding Open Access funding enabled and organized by Projekt DEAL. The research was supported by the German Federal Ministry of Education and Research (BMBF) via the research project "Neo-Indikatorik" (Funding-ID: 16IFI014).

Data Availability Only free available data has been used. Sources for the used data are mentioned in the manuscript.

Code availability There is no code available.

\section{Declarations}

Conflict of interest The authors declare no conflict of interest.

Open Access This article is licensed under a Creative Commons Attribution 4.0 International License, which permits use, sharing, adaptation, distribution and reproduction in any medium or format, as long as you give appropriate credit to the original author(s) and the source, provide a link to the Creative Commons licence, and indicate if changes were made. The images or other third party material in this article are included in the article's Creative Commons licence, unless indicated otherwise in a credit line to the material. If material is not included in the article's Creative Commons licence and your intended use is not permitted by statutory regulation or exceeds the permitted use, you will need to obtain permission directly from the copyright holder. To view a copy of this licence, visit http://creativecommons.org/licenses/by/4.0/.

\section{References}

Ahuja G (2000) Collaboration networks, structural holes, and innovation: a longitudinal study. Adm Sci Q 45: 425-455

Anderson P, Tushman ML (1990) Technological discontinuities and dominant designs: a cyclical model of technological change. Adm Sci Q 35:604-633 
Archibugi D, Planta M (1996) Measuring technological change through patents and innovation surveys. Technovation 16(9):451-519

Arora SK, Porter AL, Youtie J, Shapira P (2013) Capturing new developments in an emerging technology: an updated search strategy for identifying nanotechnology research outputs. Scientometrics 95(1):351-370

Barley SR (1986) Technology as an occasion for structuring: evidence from observations of CT scanners and the social order of radiology departments. Adm Sci Q 31:78-108

Basberg BL (1982) Technological change in the Norwegian whaling industry: a case-study in the use of patent-statistics as a technology indicator. Res Policy 11(3):163-171

Basberg BL (1987) Patents and the measurement of technological change: a survey of the literature. Res Policy 16(2-4):131-141

Baum JA, Shipilov AV, Rowley TJ (2003) Where do small worlds come from? Ind Corp Chang 12(4):697725

Berkhout F (2002) Technological regimes, path dependency and the environment. Glob Environ Chang 12(1): $1-4$

Blankenberg AK, Buenstorf G (2016) Regional co-evolution of firm population, innovation and public research? Evidence from the West German laser industry. Res Policy 45(4):857-868

BMBF (1996) Bundesbericht Forschung 1996. Drucksache 13/4554. Bonn.

BMBF (2000) Bundesbericht Forschung 2000. Drucksache 14/4229. Berlin.

BMBF (2004) Bundesbericht Forschung 2004. Drucksache 15/3300. Berlin.

BMBF (2008) Bundesbericht Forschung und Innovation 2008, Berlin

BMBF (2010) Bundesbericht Forschung und Innovation 2010, Berlin

BMBF (2014) Bundesbericht Forschung und Innovation 2014, Berlin

BMBF (2016) Bundesbericht Forschung und Innovation 2016, Berlin

BMWi (2011) Regierungsprogramm Elektromobilität, Berlin

Bodin, Ö. (2006). A network perspective on ecosystems, societies and natural resource management (Doctoral dissertation, Institutionen för systemekologi).

Borgstedt P, Neyer B, Schewe G (2017) Paving the road to electric vehicles-a patent analysis of the automotive supply industry. J Clean Prod 167:75-87

Bormann R, Fink P, Holzapfel H, Rammler S, Sauter-Servaes T, Tiemann H et al (2018) The future of the German automotive industry: transformation by disaster or by design? WISO Diskurs 10/2018

Broekel T (2019) Using structural diversity to measure the complexity of technologies. PLoS One 14(5): e0216856

Broekel T, Bednarz M (2018) Disentangling link formation and dissolution in spatial networks: an application of a two-mode STERGM to a project-based R\&D network in the German biotechnology industry. Netw Spat Econ 18(3):677-704

Buchmann, T. (2015). The evolution of innovation networks: an automotive case study. Springer.

Buchmann T, Pyka A (2015) The evolution of innovation networks: the case of a publicly funded German automotive network. Econ Innov New Technol 24(1-2):114-139

Buchmann T, Hain D, Kudic M, Müller M (2014) Exploring the evolution of innovation networks in sciencedriven and scale-intensive industries: new evidence from a stochastic actor-based approach (No. 1/2014). IWH Discussion Papers.

Burkhardt ME, Brass DJ (1990) Changing patterns or patterns of change: the effects of a change in technology on social network structure and power. Adm Sci Q 35:104-127

Chappin EJ, Ligtvoet A (2014) Transition and transformation: a bibliometric analysis of two scientific networks researching socio-technical change. Renew Sust Energ Rev 30:715-723

Cho, T. S., \& Shih, H. Y. (2011). Patent citation network analysis of core and emerging technologies in Taiwan: 1997-2008. Scientometrics, 89(3):795-811

Cowan R, Jonard N, Zimmermann JB (2007) Evolving networks of inventors. In: Innovation, industrial dynamics and structural transformation. Springer, Berlin, Heidelberg, pp 129-148

Deeds DL, Hill CW (1996) Strategic alliances and the rate of new product development: an empirical study of entrepreneurial biotechnology firms. J Bus Ventur 11(1):41-55

Dijk M, Orsato RJ, Kemp R (2013) The emergence of an electric mobility trajectory. Energy Policy 52:135145

Dosi G (1982) Technological paradigms and technological trajectories: a suggested interpretation of the determinants and directions of technical change. Res Policy 11(3):147-162

Dosi G, Nelson RR (2010) Technical change and industrial dynamics as evolutionary processes. In: Handbook of the economics of innovation, vol 1, North-Holland, pp 51-127

Dosi G, Freeman C, Nelson R, Silverberg G, Soete L (1988) Technical change and economic theory. Laboratory of Economics and Management (LEM), Sant'Anna School of Advanced Studies, Pisa, Italy. 
Ebers M, Grandori A (1997) The forms, costs and development dynamics of inter-organizational networking. In: Ebers M (ed) The formation of inter-organizational networks. Oxford University Press, Oxford, pp 265-286

Emrouznejad A, Marra M (2017) The state of the art development of AHP (1979-2017): a literature review with a social network analysis. Int J Prod Res 55(22):6653-6675

Escoufier, Y. (1970). Echantillonnage dans une population de variables aléatoires réelles.

Escoufier Y (1973) Le traitement des variables vectorielles. Biometrics 29:751-760

Fleming L (2007) Breakthroughs and the "long tail" of innovation. MIT Sloan Manag Rev 49(1):69

Fleming L, Sorenson O (2001) Technology as a complex adaptive system: evidence from patent data. Res Policy 30(7):1019-1039

Gangopadhyay S, Das Gupta A, Nachabe MH (2001) Evaluation of ground water monitoring network by principal component analysis. Groundwater 39(2):181-191

Garfield E (1955) Citation indexes for science. Science 122(3159):108-111

Geels FW (2002) Technological transitions as evolutionary reconfiguration processes: a multi-level perspective and a case-study. Res Policy 31(8-9):1257-1274

Geels FW (2005) The dynamics of transitions in socio-technical systems: a multi-level analysis of the transition pathway from horse-drawn carriages to automobiles (1860-1930). Tech Anal Strat Manag 17(4):445-476

Gilsing V (2005) The dynamics of innovation and interfirm networks: exploration, exploitation and coevolution. Edward Elgar Publishing

Glasmeier A (1991) Technological discontinuities and flexible production networks: the case of Switzerland and the world watch industry. Res Policy 20(5):469-485

Gomes-Casseres B (2006) How alliances reshape competition. In: Shenker O, Jeffery J (eds) Handbook of strategic alliances. Reuer

GPTO (2007). Annual Report 2007 - German Patent and Trade Mark Office.

Griliches Z (1979) Issues in assessing the contribution of research and development to productivity growth. Bell J Econ 10:92-116

Gulati R, Gargiulo M (1999) Where do interorganizational networks come from? Am J Sociol 104(5):14391493

Hall BH, Lotti F, Mairesse J (2009) Innovation and productivity in SMEs: empirical evidence for Italy. Small Bus Econ 33(1):13-33

Hekkert, M. P., Suurs, R. A., Negro, S. O., Kuhlmann, S., \& Smits, R. E. (2007). Functions of innovation systems: A new approach for analysing technological change. Technological forecasting and social change, 74(4):413-432.

Hofbauer G, Sangl A (2019) The German automotive industry as a driving force for innovation. Am J Eng Res 8(10):90-99

Huenteler J, Ossenbrink J, Schmidt TS, Hoffmann VH (2016) How a product's design hierarchy shapes the evolution of technological knowledge - evidence from patent-citation networks in wind power. Res Policy 45(6):1195-1217

Hughes TP (1987) The evolution of large technological systems. The social construction of technological systems: new directions in the sociology and history of technology 82

Jackson MO, Wolinsky A (1996) A strategic model of social and economic networks. J Econ Theory 71(1): 44-74

Jaffe AB, De Rassenfosse G (2019) Patent citation data in social science research: overview and best practices. In Research handbook on the economics of intellectual property law. Edward Elgar Publishing

Johnson SC (1967) Hierarchical clustering schemes. Psychometrika 32(3):241-254

Josse J, Holmes S (2016) Measuring multivariate association and beyond. Statistics surveys 10:132-167

Josse J, Pagès J, Husson F (2008) Testing the significance of the RV coefficient. Computational Statistics \& Data Analysis 53(1):82-91

Joung J, Kim K (2017) Monitoring emerging technologies for technology planning using technical keyword based analysis from patent data. Technol Forecast Soc Chang 114:281-292

Kajikawa Y, Takeda Y (2008) Structure of research on biomass and bio-fuels: a citation-based approach. Technol Forecast Soc Chang 75(9):1349-1359

Kim E, Cho Y, Kim W (2014) Dynamic patterns of technological convergence in printed electronics technologies: patent citation network. Scientometrics 98(2):975-998

Klingenberg CP (2009) Morphometric integration and modularity in configurations of landmarks: tools for evaluating a priori hypotheses. Evol Dev 11(4):405-421

Koka BR, Madhavan R, Prescott JE (2006) The evolution of interfirm networks: environmental effects on patterns of network change. Acad Manag Rev 31(3):721-737 
Lacasa ID, Grupp H, Schmoch U (2003) Tracing technological change over long periods in Germany in chemicals using patent statistics. Scientometrics 57(2):175-195

Lee S, Lee S, Seol H, Park Y (2008) Using patent information for designing new product and technology: keyword based technology roadmapping. R\&D Manag 38(2):169-188

Lee WS, Han EJ, Sohn SY (2015) Predicting the pattern of technology convergence using big-data technology on large-scale triadic patents. Technol Forecast Soc Chang 100:317-329

Leydesdorff L, Carley S, Rafols I (2013) Global maps of science based on the new Web-of-Science categories. Scientometrics 94(2):589-593

Liu W, Gu M, Hu G, Li C, Liao H, Tang L, Shapira P (2014) Profile of developments in biomass-based bioenergy research: a 20-year perspective. Scientometrics 99(2):507-521

Lyu L, Wu W, Hu H, Huang R (2019) An evolving regional innovation network: collaboration among industry, university, and research institution in China's first technology hub. J Technol Transf 44(3):659-680

Madani F (2015) 'Technology Mining' bibliometrics analysis: applying network analysis and cluster analysis. Scientometrics 105(1):323-335

Madhavan R, Grover R (1998) From embedded knowledge to embodied knowledge: new product development as knowledge management. J Mark 62(4):1-12

Meckling J, Nahm J (2018) When do states disrupt industries? Electric cars and the politics of innovation. Rev Int Polit Econ 25(4):505-529

Mikler J, Harrison NE (2012) Varieties of capitalism and technological innovation for climate change mitigation. New political economy 17(2):179-208

Mogoutov A, Cambrosio A, Keating P, Mustar P (2008) Biomedical innovation at the laboratory, clinical and commercial interface: a new method for mapping research projects, publications and patents in the field of microarrays. Journal of Informetrics 2(4):341-353

Moldoveanu MC, Baum JA, Rowley TJ (2003) Information regimes, information strategies and the evolution of interfirm network topologies. Research in multi-level issues 2:221-264

Murray F (2002) Innovation as co-evolution of scientific and technological networks: exploring tissue engineering. Res Policy 31(8-9):1389-1403

Myers G (1995) From discovery to invention: the writing and rewriting of two patents. Soc Stud Sci 25(1):57-105

Niu R, Varshney PK (2007) Performance analysis of distributed detection in a random sensor field. IEEE Trans Signal Process 56(1):339-349

Orsenigo L, Pammolli F, Riccaboni M (2001) Technological change and network dynamics: lessons from the pharmaceutical industry. Res Policy 30(3):485-508

Owen-Smith J, Powell WW (2004) Knowledge networks as channels and conduits: the effects of spillovers in the Boston biotechnology community. Organ Sci 15(1):5-21

Ozman M (2009) Inter-firm networks and innovation: a survey of literature. Econ Innov New Technol 18(1): 39-67

Parraguez P, Škec S, e Carmo DO, Maier A (2020) Quantifying technological change as a combinatorial process. Technol Forecast Soc Chang 151:119803

Phlippen S, Riccaboni M (2007) Radical innovation and network evolution: the effect of the genomic revolution on the evolution of the pharmaceutical R\&D network. Annales d'Economie et de Statistique: $325-350$

Pilkington A, Dyerson R (2006) Innovation in disruptive regulatory environments. Eur J Innov Manag 9:7991

Pittaway L, Robertson M, Munir K, Denyer D, Neely A (2004) Networking and innovation: a systematic review of the evidence. Int J Manag Rev 5(3-4):137-168

Powell WW, White DR, Koput KW, Owen-Smith J (2005) Network dynamics and field evolution: the growth of interorganizational collaboration in the life sciences. Am J Sociol 110(4):1132-1205

Robert P, Escoufier Y (1976) A unifying tool for linear multivariate statistical methods: the RV-coefficient. J R Stat Soc: Ser C: Appl Stat 25(3):257-265

Roijakkers N, Hagedoorn J (2006) Inter-firm R\&D partnering in pharmaceutical biotechnology since 1975: trends, patterns, and networks. Res Policy 35(3):431-446

Rosenberg N (1982) Inside the black box: technology and economics. Cambridge University Press, New York

Simkin SM (1974) Measurements of velocity dispersions and doppler shifts from digitized optical spectra. Astron Astrophys 31:129

Smilde AK, Kiers HA, Bijlsma S, Rubingh CM, Van Erk MJ (2009) Matrix correlations for high-dimensional data: the modified RV-coefficient. Bioinformatics 25(3):401-405

Strogatz SH (2001) Exploring complex networks. Nature 410(6825):268-276

Strumsky D, Lobo J, Van der Leeuw S (2012) Using patent technology codes to study technological change. Econ Innov New Technol 21(3):267-286 
Tomic O, Forde C, Delahunty C, Næs T (2013) Performance indices in descriptive sensory analysis-a complimentary screening tool for assessor and panel performance. Food Qual Prefer 28(1):122-133

Tonry J, Davis M (1979) A survey of galaxy redshifts. I-Data reduction techniques. Astron J 84:1511-1525

Uzzi B, Mukherjee S, Stringer M, Jones B (2013) Atypical combinations and scientific impact. Science 342(6157):468-472

van der Pol J, Rameshkoumar JP (2018) The co-evolution of knowledge and collaboration networks: the role of the technology life-cycle. Scientometrics 114(1):307-323

Verhoeven D, Bakker J, Veugelers R (2016) Measuring technological novelty with patent-based indicators. Res Policy 45(3):707-723

Verspagen B (2007) Mapping technological trajectories as patent citation networks: a study on the history of fuel cell research. Adv Complex Syst 10(01):93-115

Windrum P, Birchenhall C (2005) Structural change in the presence of network externalities: a co-evolutionary model of technological successions. J Evol Econ 15(2):123-148

WIPO (2019). Guide to the International Patent Classification. Accessible via: https:/www.wipo.int/edocs/ pubdocs/en/wipo_guide_ipc_2019.pdf

Yoon J, Kim K (2011) Identifying rapidly evolving technological trends for R\&D planning using SAO-based semantic patent networks. Scientometrics 88(1):213-228

Yoon B, Park Y (2004) A text-mining-based patent network: analytical tool for high-technology trend. J High Technol Manag Res 15(1):37-50

Yuan F, Miyazaki K (2014) Understanding the dynamic nature of technological change using trajectory identification based on patent citation network in the electric vehicles industry. In: Proceedings of PICMET'14 Conference: Portland International Center for Management of Engineering and Technology; Infrastructure and Service Integration. IEEE, pp 2780-2790

Zhang H, Tian J, Li J, Zhao J (2009) RV-coefficient and its significance test in mapping brain functional connectivity. In: Medical imaging 2009: biomedical applications in molecular, structural, and functional imaging, vol 7262. International Society for Optics and Photonics, p 726222 